Conclusions Antenatal steroids still confers a survival benefit in neonates born $<29$ weeks gestation and reduces short term morbidities of NEC and severe IVH, but does not have an impact on long term neurodevelopment.

\section{COMPARISON OF SOMATIC AND NEURODEVELOPMENTAL OUTCOMES OF SMALL AND LATE PRETERM INFANTS}

doi:10.1136/archdischild-2012-302724.1220

S Akar, E Aldemir, S Kavuncuoglu, S Ozbek, M Payaslı, M Cetinkaya, G Buyukkale, E Ozturegen. Kanuni Sultan Suleyman Training and Research Hospital, Istanbul, Turkey

Objective The aim of this study was to compare the somatic and neurodevelopmental outcomes of small and late preterm infants and also to determine the prenatal, natal and postnatal factors affecting these outcomes.

Methods A total of 163 infants that were born $<32$ weeks of gestation (small preterms, control group) and 240 infants born $>32$ weeks of gestation (late preterms, study group) were included to this prospective study. All infants were evaluated at postnatal 42 weeks. Neurodevelopmental outcomes of these infants were evaluated with neurological examination and Denver II Developmental Screening Test. Also somatic evaluation including the determination of the length according to Turkish children percentilles was also performed.

Results The major neurological sequele ratio was significantly higher in small preterm infants $(13.9 \%)$ compared with the late preterms (2.4\%). Apgar scores at 5 minute, need of resuscitation in delivery room and male gender were all significantly associated with an increased risk of adverse neurological outcomes. Also presence of neonatal morbidities including neonatal hypoglycemia, sepsis, bronchopulmonary dysplasia, intraventricular hemorrhage greater than stage III were also abnormal Denver results. Somatic growth failure was detected in $2 \%$ and $4.9 \%$ of the late and small preterm infants.

Conclusion Small preterm infants might have significantly higher abnormal neurodevelopmental outcomes compared with late preterms. However, late preterm infants might be routinely followedup for somatic growth and also neurodevelopmental outcomes.

\section{LATE PRETERMS HOW DO THEY MANAGE THEIR PSYCHOMOTOR DEVELOPMENT DURING THE FIRST TWO YEARS?}

doi:10.1136/archdischild-2012-302724.1221

Ş Soysal, S Beken, Ö Turan, I Hirfanoglu, K Gücüyener, E Ergenekon, S Ünal, N Altuntaş, E Kazancı, F Kulalı, E Önal, C Türkylmaz, E Koç, Y Atalay. Gazi University Hospital, Ankara, Turkey

Background and Aim The neurodevelopmental pace of late preterms during the first 2 years has hardly been investigated. Our aim was to assess longitudional neurodevelopmental status of babies of gestational ages (GA) between 34-36/7weeks (Group I), 37-40 weeks (Group II) with Bayley II Infant Development Scale (BAYLEY II) and neurologic examination done regularly and to correlate scores with the risk factors in neonatal intensive care units (NICU). Method 100 infants (Group I) 50 (Group II) were included in the study all had serial BAYLEY-II scores and neurologic examination done at the ages of $6,9,12,18,24$ months.

Results There were no difference between the total BAYLEY-II scores of the patients in both groups at all ages ( $p>0.05)$. However, the longitudional rate of change of the PDI and MDI scores of the two groups showed a different pattern. Between 6-9 months patients in group II had a higher rate of change of PDI scores than those of Group I $(\mathrm{P}<0.05)$ between $12-18$ and $18-24$ months; it was viceversa $(\mathrm{P}<0.05)$ There was no significant difference between groups regarding to the change of MDI scores at all ages. When the pooled data was evaluated; of the NICU risk factors only mechanical ventilation had an impact on BAYLEY-II scores $(p<0.05)$.

Conclusion Knowing the rate of neurodevelopmental follow up of these patient group could be important when an early individualized management is needed.

\section{NEUROCOGNITIVE OUTCOME AT 3 YEARS IN EXTREMELY LOW BIRTH WEIGHT INFANTS (VLBW) WITH CEREBELLAR HEMORRHAGE (CH)}

doi:10.1136/archdischild-2012-302724.1222

L Bassi, 0 Picciolini, M Fumagalli, M Groppo, A De Carli, S Pisoni, I Sirgiovanni, S Passera, S Gangi, F Mosca. NICU, Fondazione IRCCS Ca' Granda, Ospedale Maggiore Policlinico University of Milan, Milan, Italy

Introduction $\mathrm{CH}$ is an increasingly diagnosticated problem in VLBW, reaching up till 19\% among the ELBW due to improved neuroimaging techniques and increased VLBW survivors. The impact of $\mathrm{CH}$ on long-term neurodevolopmental outcome is still not well known.

Aim To evaluate the consequences of $\mathrm{CH}$ on neurocognitive outcome in VLBW.

Methods $\mathrm{CH}$ and other brain lesions were identified by MRI performed at TEA. The neurological development quotient (DQ) of 9 ELBW infants with $\mathrm{CH}$, without white matter (WM) lesions (median GA- 25wks, range 23-27; birth weight -BW- $710 \mathrm{~g}$, 425-980), was compared with the DQ of others two groups: 43 control VLBW infants without lesions (GA 27.7 wks, 23-33; BW $780 \mathrm{~g}$, 430-1000) and 8 VLBW babies with WM major abnormalities (GA 28.7 wks, 26-32; BW 725 g, 430-970). The DQ was evalueted at the age of 3 years with the Griffiths Mental Developmental Scales (GMDS).

Results The 3 groups were comparable for BW ( $p=0.088$ ), but not for GA ( $p=0.005)$. The CH group, compared with controls, showed: a lower not significant DQ score ( $\mathrm{p}$ 0.07), a significant lower score in the motor areas (locomotor $\mathrm{p}=0.006$, eye and hand-coordination $p=0.002$, performance $p=0.014$ ) and in the personal social skill $(p=0.05)$, not in language $(p=0.13)$ and pratical reasoning $(p=0-38)$. When compared to the WM lesions group not significant difference was found in the DQ and the other areas.

Conclusions Our data showed that $\mathrm{CH}$ plays an important role mainly in the motor and behavioral dysfunctions at long-term outcome in VLBW infants.

\section{THE EFFECT OF EXTREMELY PRETERM BIRTH ON ADULT RELATIONSHIPS}

doi:10.1136/archdischild-2012-302724.1223

K Stjernqvist, AL Hallin. Department of Psychology, Lund University, Lund, Sweden

Background The traumatic births of Extremely Preterm (EPT) infants and long hospital stay may affect parent-child interaction, the child's attachment security negatively and impact relationships in adult life.

Aim To investigate whether EPT birth affects attachment in adulthood.

Subjects 39 young EPT born adults (gestational week, mean (SD), 27 (1.0), birth-weights 990g (228)) and 39 full-term (FT) controls, all part of a South Swedish cohort born $1985-86<29^{\text {th }}$ gestational weeks. EPT spent, mean (SD) 51(20) days in NICU.

Methods Adult Attachment Interview (AAI) and WAIS-III, Wechsler Adult Intelligence Scale.

Results AAI: Significantly more EPT adults had an unsecure attachment style. $37 \%$ EPT vs. $75 \%$ FT were secure attached $(p=0.006)$. WAIS-III: There were significant differences between the EPT- and FT-groups on Full Scale IQ (FSIO), mean (SD) 92.8(15.4) vs. 105.7 (12.5), $p<0.001$. In the EPT group statistically significant 